gain by it as becoming rather irksome in some of the Alpine stations. In one famous hotel it is considered "bad form" to be an invalid and many are tempted to "bluff" the disease and joln the festive throng. The sensible ones, however, obey their medical man and profit in consequence. There are many people now who visit the Alps for pleasure and it is rather difficult for their sick friends to refrain from participating in a life which is not only unsuited to them as invalids but taxing also to sounder constitutions. Although in most of the hotels the food placed on the table is all that can be desired it can be readily understood by English people that few establishments abroad can provide beef equal to that of the young bullocks fed on Devonshire herbage or mutton of the quality obtained from the Welsh hills, so in this respect any Finglish sanatorium would be at an advantage; but in climatic conditions the British Isles can scarcely vie with the winter climate of the Alps either as to dryness, sunshine, or calmness of the atmosphere. On the other hand, everyone who has had continuous observation of phthisical patients is aware that strict supervision of the case is the all in all. This is scarcely so easy to attain now in every hotel of a leading Swiss health resort. The magnificent climate attracts those who come for the winter sports alone; and some hotel proprietors avow that they do not want invalids. Nevertheless, there are always plenty of the latter class located there or the hotels would not be filled as they are; but these people cheerfully and complacently consider themselves under "climatic treatment" and have a false sense of security engendered thereby. They enter with vigour into all amusements at hand-dancing, skating, tobogganing, walking, \&c.-to the utmost extent of their powers. It is only the cautious poitrinaire who obtains full benefit of a prolonged absence from home. The ambiguous term "climatic treatment of consumption" is rather misleading and may warrant some invalids in assum. ing that all other treatment may be neglected to a great extent, or at any rate that the "climatic" remedy permits a maximum of enjoyment with a minimum of caution and no irksome restrictions of rest, quietude and patience anteceding the period when exercise of some kind can be prescribed with advantage.

There are assuredly many who would gladly avail themselves of some home sanatorium where, modestly speaking, two or three months' medical guidance would help to abate the feverishness and cardiac irritability so often accompanying an early deposit of tubercle in the lung; and perhaps train the patient in the way he should go afterwards, or put some flesh on him if emaciated preparatory to going abroad. Sanatoriums in England, especially during the summer months, ought to have as great a range of efficiency and utility as similar institutions established in Silesia and the Black Forest, where climate is certainly a secondary consideration, but medical supervision, diet, and hygiene of first value and importance. A not inconsiderable advantage is the mental effect produced on some patients entering an establishment devoted to one object and conducted under medical supervision which they know to be experienced in the treatment of their malady. They then appear to fall willingly into a determination to pursue the "cure" conscientiously and are saved all the officious meddling of busybodies or hotel acquaintances who, chiefly out of curiosity and want of occupation, inquire into the symptoms and offer remedies or irresponsible advice to disconcert the patient or exasperate the medical attendant.

In a well-ordered abode for receiving cases there need be no superfluous restraint or fussy, mysterious rules. For instance, one cannot see the necessity of enjoining patients to take their temperatures four times a day in the rectum as is the habit pursued in one German sanatoriam. It seems to me that the daily life of a patient can be made interesting and pleasant enough without such inconvenient occupations.

Montreux, Feb. 25th, 1898. I am, Sirs, yours faithfully, TUCK WI WISE.

\section{"HOSPITAL ABUSE."}

\section{To the Editors of THF LANOHT.}

SIns, -As your Commissioner in his article on the above subject in THE LANCET of this week referred to me in connexion with the Bradford Children's Hospital, you will, perhaps, kindly allow me to correct some inaccuracies he has fallen into, as well as to point out some injustices he has, in my opinion, committed. In the first place, as I have always been an ardent advocate of hospital reform I particularly feel any imputation of implication with hospital abuse. I have at no time been "principal surgeon" to the institution. I was from the foundation of the hospital fifteen years ago till last year-when I was appointed honorary consulting medical officer-one of a staff of three honorary medicel officers. I was also, no doubt, for the same fifteen years its honorary secretary, a not such an unusual occurrence in a new hospital. I think, as your Commissioner imagines, The Bradford Children's Hospital's constitution was founded upon that of the best similar institutions in existence, with the important qualification that special rules were introduced (notably the rule not requiriing letters of recommendation) to prevent hospital abuse. It is in no manner or shape connected with the Fye and Kar Hospital, nor were its rules at all founded on those of that institution. The fact of its employing the same collector and secretary is parely acci. dental and in no way affects the management. The Bradford Children's Hospital is the only hospital in the town, and one of the few in the country, that requires, and indeed issues, no "letters of recommendation." It has always acted upon its rale that "sickness, poverty, and childhood" alone qualify for admission. Out of an expenditure of £2083 last year only $£ 62$ were received from patients.

The house committee do not see parents for the purpose of " bargaining what they are to pay for the treatment of their children." The rule was adopted some years ago at my suggestion with the sole object of checking hospital abuse. The practice is as follows: Cases are admitted into the hospital upon the authority of the medical officer for the week or of the resident medical officer acting for him. Upon admission a card is sent to the parent requesting his attendance at the next house committee, when his circum. stances are inquired into and if he is found to be able to afford to treat the child at home the case is discharged. If not, but still in the opinion of the committee able to pay some trifle, the charitable nature of the institution is pointed out to him and he is invited to give what he is able towards the maintenance of his child, and sums of sixpence are much commoner than those of $10 \mathrm{~s}$. No one is urged to give and the donation is never either given or received as payment A large proportion are registered as unable to contribute Personally I have always been adverse to any payments from patients, but in a commercial community some concession must be made to the commercial instinct.

Hoping to have cleared our hospital from the strictures of your Commissioner, I am, Sirs, yours faithfully,

$$
\text { W. GILCHRIST BURNIE, }
$$
Hon. Consulting Medical Officer to the Bradiord
Bradford, March 30th, 1898.

To the Editors of THE LANOET.

SIRs,-My attention has been drawn to the article on "Hospital Abuse" in your issue of March 26th and, so far as it is written with the desire to assist in the remedies of abuses, I myself, in common with all persons interested in hospital work, approve of its intention, bat with others I could wish, were it possible, that your Commissioner were able with the admonition to point an effectual remedy for the abuses to which he refers. $M y$ purpose in writing to you is merely on behalf of the Bradford Children's Hospital to correct some more or less serious inaccuracies which have crept into the statement. In the first place, it is incorrect to state that "the greater number of the in-patients are made to contributs towards their maintenance in the hospital," and again that the parents have "in fact to bargain as to what they are to pay for the treatment of their children in the hospital, "and again that in appearing before the hospital committes "they must expect to be severely questioned as to their ability to pay something if the sufferer is to be admitted as an in-patient." $A s$ a matter of fact, the parents of the children do not go before the hospital com. mittee until the children are actually in-patients of the institution and far from "bargaining" with their guardians as to what they are to pay or from any compulsion being exercised towards them it is the invariable rule after inquiring into the circumstances of the family to leave the representatives absolutely and wholly free them. selves to assess the amount which they think they can give to the institution and instead of the avarage amount being 
as your article states, $2 s .6 d$. per week, I should say that 18. $6 d$. would be a fair average, and certainly this estimate is justified on reference to our report, from which it will be seen that the whole of the payments for patients during the past year was $\$ 6212 s$. Assuming the average to be, as I have stated, 1s. $6 d$. per week, the cost of a bed in the hospital averages some 15s. or $16 s$. weekly, and therefore in the case of these so-called paying patients there is a large margin of charity. The qualifications for entry to our hospital are poverty and sickness, but I apprehend that the poverty here referred to never was intended to mean the poverty of the pauper, who has a legal right to attendance in our workhouses, but is rather the poverty of above that class, and below the "affluence" which will admit of the payment for medical advice and for proper and skilled treatment at home, and that in dealing with these cases we are exercising to a full extent the charitable object of our institution. It may be that sometimes persons not answering to this description obtain the benefit of our charity, but I am satisfied that the course we adopt, and I have already shown is not of an inquisitorial or galling character and is as good a saleguard as has hitherto been found to protect against abuses, as the system of recommendations, which it seems to me is the only other alternative, lends itself far more readily to impositions. From my experience the mere fact of taking payment from the parents of the patients does not induce them in any way to conclude that they are no longer in receipt of charity, or rather (to put it in a preferable manner) receiving benefits far in excess of that for which they pay; and I have never heard any com. plaints being made such as those referred to, but, on the other hand, we do receive from time to time from so-called paying and non-paying patients alike expressions of gratitude for the benefits received. I should not have thought it necessary to write in reply to your article (although, as you will see, I take exception to the general bearing of it), so far as regards the institution with which I am connected, had it not been for the charge of compulsion in respect of payments made against our committee, as it appears to me that this is of such a serious character that I ought to lose no time in removing the wrong impression which such a statement would be likely to canse, and in doing this I naturally take the opportunity of assuring you that whilst maintaining the efficiency of our hospital we anxionsly and jealously watch over the interests of our subscribers and take every precaution possible that the benefits of our charity are not abused.

I am, Sirs, yours truly,

HERBEBT J. JHFFERY,

Bradford, March 30th, 1898

Honorary Secretary, Bradford Children's Hospital.

\section{THE VACCINATION BILL.}

\section{To the Editors of THE LANOET.}

SIRs, - I wish with your permission to draw attention to the following points in the Vaccination Bill. Bome of the opposition to the Act as it now stands is, I am sure, due to the fact that parents who wish to have their children vaccinated gratuitously must perforce go to the public vaccinator and are thus deprived in many instances of the services of their usual medical attendant, who possesses their confidence. It the new Vaccination Bill comes into force as it now stands the pablic vaccinator having to pay domiciliary visits will become a sort of authorised " tont," calling upon the patients of other medical men and requesting permigsion to operate on them. He will thus in many instances deprive his confrires of a fee.

Having ventured on this criticism, may I suggest the following alterations? Any medical man should, I think, be allowed the usual fee from the sanitary anthority for every snccessful case that is reported to it by him. The sanitary anthority should periodically send to the public vaccinatior a list of children in the district who have reached the age of twelve months, and as to whose vaccination they have had no return. It would then become the duty of that official to call on the defaulting parents and to offer his services. Parents who desire the services of the public vaccinator before the child reaches the age of twelve month should be at liberty to request his services.

I am, Sirs, yours faithfully,

March 28th, 1898.

Not a Public Vaccinator.
NOTES FROM INDIA.

(From our Special Correspondent.)

\section{The Symptoms following Inoculation for Plague with} M. Haffkine's Prophylactio F'luid.

As might be expected the symptoms following $\mathbf{M}$. Haffkine's prophylactic inoculation vary considerably in different individuals. There are many symptoms, however, which are more or less common to all. It would be likely also that the chief symptoms would resemble in a very minor degree those of plagus itself. There are, however, symptoms in plague which have no representatives, so to speak, among the symptoms following inoculation. The first indications of systemic affection occur within six hours after inoculation and consist of a sensation of chilliness, with headache, a rise of temperature and pulse, and a general feeling of malaise. There are no local symptoms at first beyond perhaps a slight red blush at the site of inoculation. The general symptoms increase and continue generally for two or three days. Vomiting sometimes occurs and occasionally diarrhœa. The temperature seldom rises beyond $103^{\circ} \mathrm{F}$., more frequently it is below $102^{\circ}$. Weakness is sometimes very marked and the pulse is feeble. Headache is often very severe. Locally an inflammatory infiltration develops which becomes extremely tender. This extreme tenderness is as characteristic after inoculation as that of the enlarged glands in plague. No enlargement of the adjacent lymphatic glands occurs and only very occasionally does suppuration ensue at the site of inocalation. Desquamation of the cuticle over the inflamed area frequently follows. The local symptoms linger for several days after the patient has apparently recovered his usual health, which is most commonly in from four to eight days. The local and general symptoms are sometimes very slight, whilst at other times they are not only very severe but last perhaps eight days or more and are followed by considerable weakness.

The less frequent symptoms, perhaps depenỏing upon personal idiosy ncrasy, are very interesting. The minor complaints are joint pains without any swelling, lasting perhaps a fortnight. There is an erythematous rash more or less all over the body and sometimes a distinct urticaria is seen. No papules or pustules have been observed. A certain amount of anæmia and emaciation occurs in a few people, and some complain that they have never felt well since the inoculation. General weakness, loss of appetite, and constipation for some little time afterwards have been more frequently complained of, and a weakness in the lower extremities has been occasionally observed. A few people seem to develop mental excitement and a feeling of unrest; others become irritable in temper for a week or more. Confusion of ideas, a nasty clammy taste in the mouth, and a.dry cough lasting for about a week are comparatively common. Nursing mothers have been inoculated without any disturbance to the child and pregnant women have not developed any untoward symptoms. The menstrual period seems sometimes to be anticipated, and if the flow has commenced at the time of inoculation it is subsequently increased in quantity. Sexual excitement has been mentioned as having occurred in a few cases.

It is not surprising on comparison with the effects of other toxin feverish attacks to find that certain ailments should be actually improved. Some asthmatic patients seem considerably relieved and even apparently cured for several months by this inoculation. Chronic eczematous conditions, especially in children, appear also to derive some benefit. Some apparently healthy people have even voluntarily stated that they have improved in their general health.

such are the symptoms following what is practically a mild dose of the toxin developed by the artificial culture of the plague bacillus. The severer symptoms of plague itself are probably explained by the more frequent and larger dosage of the toxin into the general circulation and perhaps to the actual presence of the bacilli in certain parts. The enlargement of the lymphatic glands so characteristic of plague appears to be due to the presence of the bacillus, as it does not occur after inoculation. Blebs on different parts of the body as well as the cellulo-cutaneous infiltration followed by sloughing, both of which are common in plague, have no representative symptoms after inoculation. The so-called palmonary variety of plague, attended by extensive lobular pneamonia and cedema, with the presence of bacilli in the sputum, is also unrepresented among the symptoms following 